\title{
Asidik Çözeltide Yumuşak Çeliğin Korozyonu Üzerine Yeşil İnhibitör Olarak Morus Nigra Pendula Yaprak Ekstraktının İnhibisyon Etkisinin İncelenmesi
}

\author{
Ayșe ONGUN YÜCE ${ }^{* 1}$ \\ ${ }^{1}$ Çukurova Üniversitesi, Fen-Edebiyat Fakültesi, Kimya Bölümü, Adana
}

Geliş tarihi: 09.01.2019

Kabul tarihi: 27.03.2019

$\ddot{O} z$

Morus Nigra Pendula yaprağı ekstresinin (MNPYE) inhibisyon davranışı, 0,5 M HCI çözeltisi içinde farklı konsantrasyonlarda yeşil bir korozyon inhibitörü olarak yumuşak çelik (YÇ) için, doğrusal polarizasyon direnci (LPR), elektrokimyasal impedans spektroskopisi (EIS) ve potansiyodinamik polarizasyon teknikleri kullanılarak araştırılmıştır. EIS ölçümleri, asit çözeltisınde MNPYE'nin artan konsantrasyonuyla yük transfer direncinin arttığını ve çift tabaka kapasitansının azaldığını göstermiştir. Polarizasyon ölçümleri, MNPYE'nin hem anodik hem de katodik akım yoğunluğu değerlerini azaltan karışık tipte bir inhibitör olduğunu göstermiştir. MNPYE bileşenlerinin YÇ yüzeyindeki adsorpsiyonu, Taramalı Elektron Mikroskobu (SEM) verileri ile karakterize edildi.

Anahtar Kelimeler: Yumuşak çelik, EIS, Korozyon, Adsorpsiyon

\section{Investigation of Inhibition Effect of Morus Nigra Pendula Leaf Extract as Green Inhibitor on The Corrosion of Mild Steel in Acidic Solutions}

\begin{abstract}
The inhibition behavior of Morus Nigra Pendula leave extract (MNPYE) as a green corrosion inhibitor in 0.5 M HCI solution at dissimilar concentrations for mild steel (MS) was investigated using methods such as linear polarization resistance (LPR), electrochemical impedance spectroscopy (EIS) and potentiodynamic polarization techniques. EIS measurements have shown that the rising concentration of MNPYE in the acid solution increments the charge transfer resistance and diminishes the double layer capacitance. Polarization measurements have shown that MNPYE is a mixed-type inhibitor which diminishes both anodic and cathodic current density values. The adsorption of MNPYE components on the MS surface was characterized by scanning electron microscopy (SEM) data.
\end{abstract}

Keywords: Mild steel, EIS, Corrosion, Adsorption

*Sorumlu yazar (Corresponding author): Ayșe ONGUN YÜCE, ayseongunyuce@ gmail.com 


\section{GİRIŞ}

Asitlerin endüstriyel uygulamalarda temizleyici olarak kullanılması esnasında yumuşak çeliğin (YÇ) korozyonunun önlenmesi için asit çözeltisinin inhibe edilmesi gerekir. Bu amaçla çoğunlukla inhibitörler kullanılır. Asidik ortamlarda çevre dostu inhibitörler kullanarak metallerin inhibisyonunun araştırılması, günümüzdeki mevcut araştırmaların önemli konularından biridir [1-4]. Asitlerin korozif olması nedeniyle, dünya genelinde metalik parçaların hızlı aşınmasından kaynaklanan ciddi bir ekonomik kayıp yaşanmaktadır. Yukarıdaki işlemleri kontrollü bir korozyon ortamında gerçekleştirmek için zaman zaman korozyon inhibitörleri olarak bir dizi organik bileşik çalışılmış ve kullanılmıştır [5,6]. Ancak, yüksek maliyet ve artan sağlık ve ekolojik risk bilincinin bir sonucu olarak, yüksek verimli, daha ucuz ve toksik olmayan inhibitörler bulmak için araştırmaya başlanmıştır. Çevre dostu korozyon inhibitörleri konusundaki araştırmalardaki mevcut eğilim, düşük maliyet ve çevre dostu olmalarından ötürüdür. Doğal ürünler arasında, bitki özleri öne çıkmaktadır. Bitki ekstrelerinde bol miktarda bulunan suda çözünebilir fotokimyasal bileşenler, ucuz, toksik olmayan ve yenilenebilir kaynaklar olarak önemli bir potansiyele sahiptir. Bu doğal ürünlerin verimi ve ayrıca bitki ekstraktlarının korozyon önleme yetenekleri, bitki ve bitkinin bölümlerine bağlı olarak büyük ölçüde değişmektedir [7]. Kök, tohumlar, yapraklar, gövde, çiçek ve meyveler gibi bitkinin farklı bölümlerinin özü, asidik ortamda çeşitli demir ve demir dışı metallerin korozyon hızını azaltmak için inhibitör olarak kullanılabilir. Nauclea latifolia [8], Oxandra asbecki [9], Marigold flower [10], Neolamarckia cadamba [11], Justicia gendarussa [12] ve Hunteria umbellata seed [13] bitki ekstrelerinin asit korozyonu için iyi inhibitörler oldukları bildirilmiştir. Ekstraktların temel bileşenleri şekerler, steroidler, glikozitler, terpenoidler, flavanoidler, vs.'dir. Türkiye'de pekmez, pestil ve kome olarak bilinen dut ürünleri uzun zamandir Anadolu'da yaygin olarak tüketilmektedir. Dutun (Morus) bazı kimyasal ve fiziksel özelliği onun kalitesini etkilemektedir. Cins Morus (M), 14 tür ağaç ve canlılardan oluşur. Tanınmış dut türleri M. alba, M. nigra, M. rubra, M. australis, M. latifolia, M. multicaulis ve M. bombycis'dir. Dutlar, Asya, Avrupa ve Kuzey Amerika'nın 1lıman ve subtropik bölgelerine özgüdür. Her ne kadar M. nigra'nın köken yeri hâlâ belirleniyor olsa da Bellini ve arkadaşları [14] M. nigra'nın Kuzey İran, Türkiye, Suriye, Arabistan, Asya Rusya'nın güneyinde yer aldığını ve Avrupa, ABD, Avustralya, Asya Rusya ve Hindistan'ın güneyinde yetiştirildiğini bildirmiştir. Dutun farklı kısımları çeşitli amaçlarla kullanılmaktadır. Yapraklar oldukça besleyicidir ve $\mathrm{B}, \mathrm{C}, \mathrm{D}$ vitaminleri ve flavonoidleri içerir. Bazen sebze, taze meyve veya meyve suyu olarak kullanılırken bazen de yaprakları ve genç dalları ağır soğuk algınlığı, öksürük, kırmızı göz, böcek 1sırıkları ve yaraların tedavisinde kullanılır. Taze yapraklar ayrica yemeklerde veya salatalarda kullanılmaktadır. Bu doğal atıkların başarılı bir şekilde kullanılması, kaynakların geri kazanımı için bir seçenek de sağlayabilir. MNPYE, potansiyel bir korozyon önleyici olarak görev yapabilir. Literatürde YÇ korozyonunun önlenmesi için MNPYE'nin kullanımı bildirilmemiştir. Bu çalışma, lineer polarizasyon, potansiyodinamik polarizasyon, yüzey analizi (SEM, FT-IR) ve elektrokimyasal empedans spektroskopisi ölçümleri kullanılarak YÇ için MNPYE'nin korozyon önleyici özelliklerini ve inhibisyon mekanizmasını araştırmayı amaçlamaktadır. Bir inhibitör olarak MNPYE'nin seçimi, YÇ yüzeyine adsorpsiyon için aktif merkezler içeren fotokimyasal bileşenleri (şekerler, steroidler, glikozitler, terpenoidler, flavanoidler, vb) bulundurmasından dolayıdır.

\section{2. ÖNCEKİ ÇALIŞMALAR}

Bazı organik ve inorganik kimyasal inhibitörlerin kullanımı, sentez bileşiklerinin çok pahalı oluşu, biyo-bozunabilirlik özelliklerinin yeterli olmaması, insan ve çevre için toksik ve tehlikeli olmalarından dolayı kısıtlıdır. Son araştırmalar bitki ekstrelerinin korozyon önleme özelliklerine odaklanmıştır. Garai 
ve arkadaşları, Artemesia pallensin ham metanolik ekstraktından aktif ana maddesi olan Arbutin'in, $30{ }^{\circ} \mathrm{C}$ 'de $400 \mathrm{mg} / \mathrm{L}$ konsantrasyonunda $1 \mathrm{M} \mathrm{HCI}$ çözeltisi içindeki yumuşak çelik için inhibisyon veriminin sirasıyla \%93 ve \%98 olduğunu bildirmişlerdir [15]. Li ve arkadaşları bambu yaprağı ekstresinin iki ana bileşiğinin rutin ve orientinin, $0,1 \quad \mathrm{M} \quad \mathrm{H}_{3} \mathrm{PO}_{4}$ solüsyonunda soğuk haddelenmiş çeliğin (CRS) korozyonu için orta düzeyde inhibitörler olarak hareket ettiğini bildirmişlerdir. Gravimetrik ölçümlerde $25^{\circ} \mathrm{C}$ 'de $100 \mathrm{mg} / \mathrm{L}$ konsantrasyonlarında İnhibisyon verimleri ise şu sırada bulunmuştur: yaprak ekstresi $(\% 51,2)>$ rutin $(\% 42,5)>$ orientin $(\% 34,0)$ [16]. Akasya sakızı, özellikle de Acacia Senegal'den, süt, şekerleme ve unlu mamüllerin hazırlanmasında kullanılan bir g1da katkı maddesidir [17]. Umoren ve ark. tarafindan alkali ortamda $333 \mathrm{~K}$ 'da $0,5 \mathrm{~g} / \mathrm{L}$ akasya sakızı konsantrasyonunda alüminyum korozyonu için \%76 inhibisyon verimliliği bulmuşlar ve akasya sakızını bir inhibitör olarak belirtmişlerdir [18]. Ayrıca, Umoren, hem yumuşak çelik hem de alüminyum için sülfürik asitli ortamda korozyon inhibitörü olarak arap zamkını incelemiştir. En yüksek inhibisyon verimini $333 \mathrm{~K}$ 'de $0,5 \mathrm{~g} / \mathrm{L}$ arap zamkı içeren asidik ortamda yumuşak çelik için \%38 ve alüminyum için 303 K'de \%80 oranında gözlemlemiştir. Yumuşak çelik için kimyasal adsorpsiyon ve alüminyum korozyonu için fiziksel adsorpsiyon önermiştir [19].

\section{MATERYAL VE METOT}

\subsection{Bitki Ekstraktlarının Hazırlanması}

Şehrimizdeki Morus (M) Nigra Pendula ağaçlarından toplanan taze yapraklar damıtılmış su ile yıkand1, $25{ }^{\circ} \mathrm{C}$ 'de vakumlu firında kurutuldu, küçük parçalar halinde toz haline getirildi. $6,00 \mathrm{~g}$ toz halindeki yapraklar, 6 saat $30{ }^{\circ} \mathrm{C}$ 'de $100 \mathrm{~mL}$ sulu etilasetat (50:50) içinde ultrasonik banyoda bekletildi. Sonra, elde edilen çözelti ayırma hunisi ile ayrıldı. Ayrılan sulu çözelti, özü elde etmek için aynı sıcaklıkta 2 saat süreyle ultrasonik banyoda bekletildi. Daha sonra ekstrakt bir filtre kağıdıyla filtre edildi ve filtrelemeden sonra, dut yapraklarının stok çözeltileri $(0,12,0,40,1,20$,
2,00 $\mathrm{gL}^{-1}$ ) 0,5 M HCI ile hazırland 1 ve testlerde korozyon inhibitörü olarak kullanıldı.

\subsection{Elektrotların ve Test Çözeltilerinin Hazırlanması}

Çalışma elektrotları, ağırlıkça kimyasal bileşime (\%: 0,263 C; 0,11 Si; 0,034 S; 0,023 P; 0,012 Cr; $0,01 \mathrm{Mn}$ ve geride kalan kısım Fe) sahip, silindir şeklinde YÇ çubuktan $5 \mathrm{~cm}$ 'lik parçalar kesilerek hazırlanmıştır. Kesilen parçaların $0,2 \mathrm{~cm}^{2}$ yüzey alanlarından biri açıkta kalacak şekilde diğer yüzey delinerek iletkenlik için bakır tel geçirildikten sonra polyester ile kaplanmıştır. Testlerden önce, her çalışma elektrodu, (100-1200 dereceli) uygun zımpara kağıtları ile mekanik parlatıcıda parlatıldıktan sonra damıtılmış su, etanol, damıtılmış su ile arka arkaya temizlenmiş ve sonrasında açık havada kurutulmuşlardır. MNPYE'nin farklı konsantrasyonları ağırlıkça (\%0,12, \%0,40, \%1,20,\%2,00), 0,5 M HCI çözeltisi ile her deney için taze olarak hazırlanmış ve ölçümler, hücre sıcaklığı kontrol edilerek $25 \pm 1{ }^{\circ} \mathrm{C}$ 'de statik koşullar altında uygulanmıştır.

\subsection{Elektrokimyasal Ölçümler ve Yüzey Analizleri}

Elektrokimyasal testler, çalışma elektrodu olarak YÇ elektrodu içeren geleneksel üç elektrot hücresinde, karşı elektrot olarak $2 \mathrm{~cm}^{2}$ yüzey alanına sahip Platin $(\mathrm{Pt})$ elektrot ve referans elektrot olarak gümüş-gümüş klorür $\mathrm{Ag} / \mathrm{AgCl}$ (3 M KCI) elektrot kullanılarak CHI 660b model A1420 seri numaralı elektrokimyasal analiz cihazı ile atmosfere açık koşullarda $298 \quad$ K'de gerçekleştirilmiştir. Korozyon işleminin inhibisyon mekanizmasını araştırmak ve aktivasyon enerjisini hesaplamak için, polarizasyon eğrileri, 298, 308, 318 ve $328 \mathrm{~K}$ sicaklıklarında $2,00 \mathrm{gL}^{-1} \mathrm{MNPYE}$ içeren 0,5 M HCI çözeltisinde 2 saat daldırmadan sonra açık devre potansiyelinde (EOCP) gerçekleştirilmiştir. Polarizasyon eğrileri $0,001 \mathrm{~V} \mathrm{~s}^{-1}$ tarama hizı ile $-0,80$ ve $-0,20 \mathrm{~V}(\mathrm{Ag} / \mathrm{AgCl})$ aralığında elde edilmiştir. EIS ölçümleri, $10^{5}-10^{-3}$ $\mathrm{Hz}$ frekans aralığında $5 \mathrm{mV}$ genlik uygulanarak ele edilmiştir. Ayrıca, doğrusal polarizasyon direnci (LPR) testleri, $0,001 \mathrm{~V} \mathrm{~s}^{-1}$ tarama hızı ile açık devre potansiyelinden $\pm 0,010 \mathrm{~V}(\mathrm{Ag} / \mathrm{AgCl})$ aralığında 
elde edilen akım-potansiyel eğrilerinden belirlendi. YÇ'nin sıfır yük potansiyelini tanımlamak için, 2,00 $\mathrm{gL}^{-1} \mathrm{MNPYE}$ içeren 0,5 M HCI çözeltisi içinde YÇ'nin farklı potansiyellerde elde edilen impedans verilerine karşılık gelen çift tabaka kapasitansı $\left(\mathrm{C}_{\mathrm{dl}}\right)$ verileri incelenmiştir.

YÇ'nin yüzey morfolojileri, YÇ elektrotun $298 \mathrm{~K}^{\prime}$ de 2,00 $\mathrm{gL}^{-1}$ MNPYE içeren ve içermeyen 0,5 M HCI çözeltisi içinde yüzey morfolojisini daha net ifade edebilmek için 2 saat daldırıldıktan sonra SEM analizörü (FESEM; Model: FEI Quanta 650) ile belirlenmiștir.

\section{BULGULAR VE TARTIŞMA}

\subsection{Elektrokimyasal İmpedans Spektrokopisi}

298 K'de farklı konsantrasyonlarda MNPYE içeren ve içermeyen YÇ için 1 saat daldırmadan sonra elde edilen EIS eğrileri (Nyquist, Bode ve Faz açısı) Şekil 1 (a), (b) ve (c)'de sırasıyla gösterilmiştir. Nyquist eğrileri incelendiğinde, yüksek frekans bölgesinden başlayıp orta frekans bölgesinde devam eden ve düşük frekans bölgesinde kapanan basık kapasitif yarım daireler içerdiği görülmektedir. Basık kapasitif yarım daireler, YÇ korozyonunun yük transfer prosesiyle kontrol edildiğini göstermektedir [20]. Her eğride bir yarım daire bir zaman sabiti anlamına gelir. Ayrıca, bu kapasitif yarım daireler, YÇ yüzeyinin homojen olmamasını, pürüzlülüğünden dolayı frekans dağılımından kaynaklanan bir şekle sahip olduğunu göstermektedir [21]. Asit çözeltisine artan konsantrasyonla MNPYE ilave edildiğinde Nyquist eğrilerinin çapının arttığı görülmektedir. Bu artış MNPYE bileşenlerinin metal yüzeyine adsorplanıp koruyucu bir film oluşturduğunu göstermektedir. Ek olarak, Nyquist eğrilerinin şeklinin her konsantrasyon için değişmemesi yük transfer mekanizmasının değişmediği anlamına gelmektedir [22]. Şekil 1 (b) ve (c)'de bode ve faz açısı eğrileri de tek yarım dairelerden oluşan Nyquist eğrilerini desteklemektedir. Nyquist eğrilerinin çap1 genellikle yük transfer direnci olarak kabul edilir [23] fakat korozyon esnasında metal/çözelti ara yüzeyinde iyon difüzyonundan, yüzeydeki birikintilerden (korozyon ürünleri, iyonlar, inhibitör molekülleri vb gibi) kaynaklanan dirençlerin ve yüzeyde oluşan filmin direncinin de katkısı unutulmamalıdır [24]. $\mathrm{Bu}$ nedenle Nyquist eğrilerinde düşük ve yüksek frekanslar arasındaki fark bu dirençlerin katkısını ifade eden polarizasyon direnci $\left(R_{p}\right)$ olarak ele alınmalıdır. Şekil 1'de MNPYE konsantrasyonunun artmasiyla $R_{p}$ değerlerinin arttığı görülmektedir. Sonuç olarak, EIS diyağramlarından elde edilen veriler birbiriyle uyumludur ve YÇ yüzeyine MNPYE bileşenlerinin adsorpsiyonunu doğrulamaktadır.
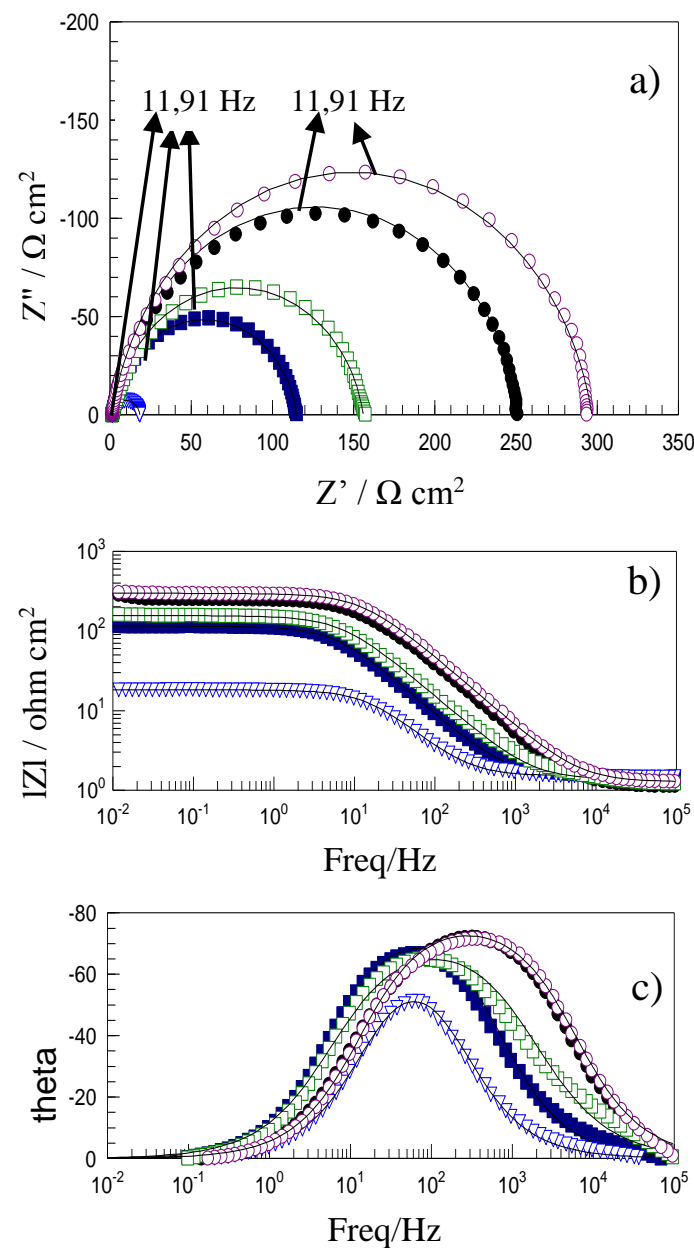

Şekil 1. 298K'de 0,5 M HCI $(\Delta)$ çözeltilerinde farklı konsantrasyonlarda MNPYE (0,12 (匹), 0,40 $\begin{array}{lll}(\square), 1,20 & (\bullet), 2,00 & \left.(\circ)\left(\mathrm{gL}^{-1}\right)\right) \text { içeren }\end{array}$ ortamlarda YÇ elektrot için elde edilen Nyquist (a), bode (b) ve faz açısı (c) eğrileri 
EIS verileri elektriksel eşdeğer devre elemanları ile gösterilmektedir. ZView2 programı ile fit edilen EIS verilerine uyan elektriksel eşdeğer devre Şekil 2'de verilmiştir. Nyquist eğrilerinden ve LPR'den belirlenen polarizasyon dirençleri, hesaplanan inhibisyon etkinlikleri ve elektriksel eşdeğer devre elemanları (çözelti direnci $\left(R_{S}\right)$, yük transfer direnci $\left(R_{c t}\right)$ and çift tabakanın sabit faz elementi $(C P E)$, (yüzey homojensizlik derecesi $(0 \leq n \geq 1))$ n) Çizelge 1'de sunulmuştur.

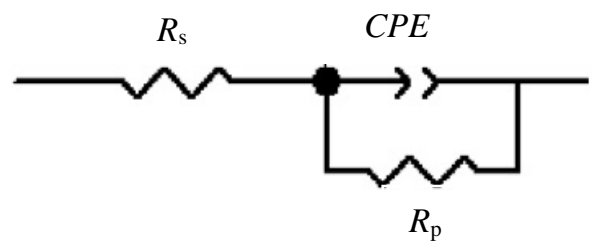

Şekil 2. Metal/çözelti arayüzeyi için kullanılan eşdeğer devre modeli (Rp: Polarizasyon direnci, Rs: Çözelti direnci, CPE: Sabit Faz Elementi)

Nyquist eğrileri EIS teorisinden beklenildiği gibi tam bir yarım daire değildir. Metal/çözelti arayüzeyinde metal tarafinda yükü oluşturan elektronların çapı, çözelti tarafında bulunan iyonlardan çok daha düşüktür. $\mathrm{Bu}$ nedenle çift tabakadaki yükü dengelemek için iyonlar diş Helmholtz tabakasından çözelti içerisine doğru sıralanmaktadır. Bu durum, arayüzeyde ideal bir kapasitör oluşumunu engellemektedir. Nyquist eğrilerinin yarım daireden sapması nedeniyle $C_{d l}$ yerine CPE kullanılmıștır [25]. MNPYE'nin varlığında $\mathrm{CPE}$ değerlerindeki düşme, dielektrik sabitindeki azalmaya ve/veya elektriksel çift tabakanın kalınlığındaki artma ya da her ikisinin birleşiminden kaynaklanmaktadır [26]. Bu durumun bir sonucu olarak, EIS ve LRP den elde edilen $R_{p}$ değerleriyle belirlenen inhibisyon verimleri de (\%IE) artmaktadır. Aşağıdaki denklemde, EIS ve LRP direnç değerleri inhibisyon verimini (\%IE) hesaplamak için kullanılmıştır.

$I E(\%)=\left(\frac{R_{p}^{\prime}-R_{p}}{R_{p}^{\prime}}\right) \times 100$

Eşitlik 1'de verilen Rp ve Rp' sırasıyla MNPYE içermeyen ve içeren ortamda elde edilen polarizasyon dirençlerini ifade etmektedir.

Çizelge 1'den de görüldüğü gibi MNPYE konsantrasyonunun artması ile eşdeğer devreye göre düzenlenen EIS verilerinden elde edilen $R_{p}, n$, değerleri artarken CPE değerleri azalmaktadır. $R_{p}$ değerlerindeki artış ve $\mathrm{n}$ değerlerinin 1 'e yaklaşması MNPYE bileşenlerinin metal yüzeyine adsorpsiyonu sonucu bariyer bir film oluşumu ve bunun sonucu olarak yüzeyin homojenliğinde bir artış ile açıklanabilir.

Çizelge 1. Farklı konsantrasyonlarda MNPYE içeren ve içermeyen 0,5 M HCl çözeltilerinde YÇ için EIS ve LPR ölçümlerinden elde edilen elektrokimyasal parametreler

\begin{tabular}{|c|c|c|c|c|c|c|}
\hline \multirow{2}{*}{$\begin{array}{c}\mathrm{C}_{\mathrm{inh}} \\
(\mathrm{g} / \mathrm{L})\end{array}$} & \multicolumn{4}{|l|}{ EIS } & \multicolumn{2}{|l|}{ LPR } \\
\hline & $\mathrm{R}_{\mathrm{p}}\left(\Omega \mathrm{cm}^{2}\right)$ & $\mathrm{CPE}\left(\mu \mathrm{F} \mathrm{cm}^{-2}\right)$ & $\mathrm{n}$ & $\eta(\%)$ & $\mathrm{R}_{\mathrm{p}}\left(\Omega \mathrm{cm}^{2}\right)$ & IE (\%) \\
\hline 0 & 16 & 927 & 0,88 & & 18 & \\
\hline 0,12 & 113 & 335 & 0,90 & 86 & 116 & 84 \\
\hline 0,40 & 154 & 202 & 0,88 & 90 & 161 & 89 \\
\hline 1,20 & 254 & 96 & 0,87 & 94 & 246 & 92 \\
\hline 2,00 & 295 & 68 & 0,90 & 95 & 305 & 94 \\
\hline
\end{tabular}

\subsection{Potansiyodinamik Polarizasyon Ölçümleri}

Şekil 3 'te, 0,5 M HCl içerisınde farklı derişimlerde MNPYE içeren ortamlarda YÇ için elde edilen akım potansiyel eğrileri verilmiştir.

Elde edilen eğrilerden, korozyon akım yoğunluğu $\left(\mathrm{i}_{\mathrm{kor}}\right)$, korozyon potansiyeli $\left(\mathrm{E}_{\mathrm{kor}}\right)$, katodik Tafel eğimi $\left(b_{c}\right)$ olmak üzere ilgili parametreler Çizelge 2'de verilmiştir. icorr değerleri, daha uzun ve daha iyi tanımlanmış bir Tafel bölgesi oluşturan katodik polarizasyon eğrilerinin korozyon potansiyellerine ekstrapolasyonu ile belirlenmiştir [27]. Eşitlik 2'de, ikorr değerleri inhibisyon verimini (\%IE) hesaplamak için kullanılmıştır. 
$\% I E=\left(\frac{i_{k o r}-i_{k o r}^{\prime}}{i_{k o r}}\right) \times 100$

$i_{\text {kor }}$ ve i' kor sırasıyla MNPYE içermeyen ve içeren ortamda elde edilen korozyon akım yoğunluğu değerleridir.

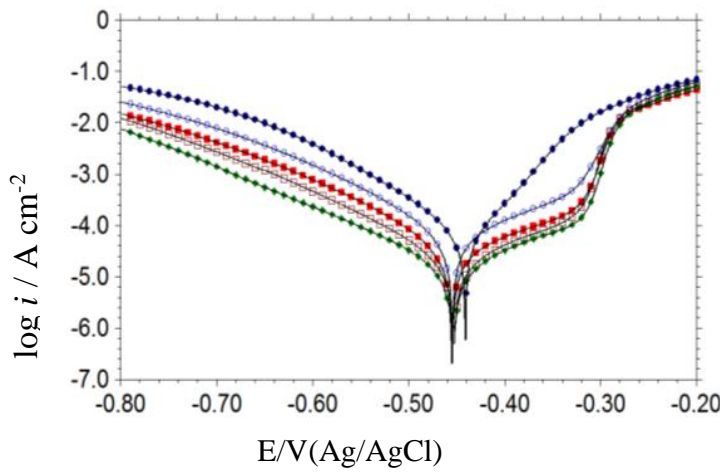

Şekil 3. 298K'de 0,5 M HCI (•) çözeltilerinde farklı konsantrasyonlarda MNPYE (0,12 (०), 0,40 $\left.(\mathbf{\square}), \quad 1,20 \quad(\square), \quad 2,00 \quad(\boldsymbol{\Delta}) \quad\left(\mathrm{gL}^{-1}\right)\right)$ içeren ortamlarda YÇ elektrot için elde edilen polarizasyon eğrileri

Şekil 3'te MNPYE'nin 0,5 M HCI çözeltisine eklenmesinden sonra YÇ'nin hem anodik çözünme reaksiyonunun hem de katodik hidrojen oluşum reaksiyonunun yavaşladığı görülmektedir. Ayrıca, bu reaksiyonların yavaşlaması, MNPYE konsantrasyonunun artmasiyla daha belirgin hale gelmektedir. Çizelge 2'den, MNPYE konsantrasyonunun artmasiyla inhibisyon veriminin arttığı ve ikor değerlerinin önemli ölçüde azaldığı açıktır, ancak $E_{\text {kor }}$ değerlerinin MNPYE içermeyen ortama göre daha negatif potansiyele doğru kaydığı gözlenmektedir [28].

Elde edilen sonuçlar, çözelti içerisindeki MNPYE'nin konsantrasyonunun artmasiyla her iki yöndeki akım değerlerinin daha da azaldığını ve buna paralel olarak korozyon potansiyelinin daha negatif potansiyellere kaydığını göstermektedir. Bu sonuç MNPYE'nin karma inhibitör olarak metal yüzeyine adsorplandığını ve daha çok katodik bölgelere etki ettiğini göstermiștir.

Şekil 3'deki paralel katodik Tafel eğrileri ve Çizelge 2'deki katodik Tafel eğimlerindeki küçük değişimler, katodik "hidrojen oluşum reaksiyonu"nun aktivasyon kontrollü olduğunu göstermektedir. MNPYE'nin 0,5 M HCI çözeltisine eklenmesi, hidrojen oluşum mekanizmasını değiştirmemekte ve $\mathrm{YÇ}$ yüzeyindeki $\mathrm{H}+$ iyonlarının indirgenmesinin esas olarak bir yük transfer mekanizması yoluyla gerçekleştiğini göstermektedir (29). Başka bir ifadeyle, MNPYE bileşenleri ilk olarak YÇ yüzeyine adsorbe olur ve bu nedenle, sadece YÇ yüzeyinin reaksiyon bölgelerini bloke ederek asit saldırısına karşı korumuş olur. $\mathrm{Bu}$ şekilde, $\mathrm{H}+$ iyonlarının indirgenmesi için mevcut olan yüzey alanı azalırken, reaksiyon mekanizması bu durumdan etkilenmemektedir (30). 0,5 M HCI'de YÇ'nin anodik polarizasyon eğrisi incelendiğinde, MNPYE'nin varlığında, belirli bir potansiyel değerine $(\sim-0,300 \mathrm{~V} /(\mathrm{Ag} / \mathrm{AgCl}))$ kadar akım yoğunluklarının azaldığı görülmektedir (31). Bu durum, bu aralıkta oksitlerin ve MNPYE bileşenlerini içeren anodik koruyucu filmin oluşumu ile açıklanmaktadır. Bu bölgede, MNPYE bileşenlerinin adsorpsiyon hızı yüksektir ve YÇ'nin korozyon hızının azaldığı görülmektedir. Ancak, MNPYE'nin varlığında, bu potansiyel değerinden sonra ise MNPYE bileşenlerinin adsorpsiyon hızı azalmakta ve desorpsiyon hızı arttığı için hızlı bir şekilde metal çözünmesi gerçekleşmektedir. Bu nedenle, bu potansiyel değeri desorpsiyon potansiyeli olarak ifade edilmektedir.

Çizelge 2. YÇ için polarizasyon ölçülerinde belirlenen elektrokimyasal parametreler

\begin{tabular}{|c|c|c|c|c|}
\hline $\begin{array}{c}C_{\text {inh }} \\
(\mathrm{g} / \mathrm{L})\end{array}$ & $\begin{array}{c}E_{\text {korr }} \\
(\mathrm{V}, \mathrm{Ag} / \mathrm{AgCl})\end{array}$ & $\begin{array}{c}i \\
\text { kor } \\
\left(\mathrm{mA} \mathrm{cm}^{-2}\right)\end{array}$ & $\begin{array}{c}-b c \\
\left(\text { V dec }^{-1}\right)\end{array}$ & $\begin{array}{c}I E \\
(\%)\end{array}$ \\
\hline 0 & $-0,457$ & 1,210 & 113 & \\
\hline 0,12 & $-0,479$ & 0,373 & 113 & 69 \\
\hline 0,40 & $-0,480$ & 0,235 & 112 & 81 \\
\hline 1,20 & $-0,480$ & 0,150 & 115 & 88 \\
\hline 2,00 & $-0,484$ & 0,069 & 116 & 94 \\
\hline
\end{tabular}

\subsection{Adsorpsiyon İzotermi}

MNPYE bileşenleri ile YÇ yüzeyi arasındaki etkileșim tipi hakkında daha fazla bilgi edinmek için, farklı konsantrasyonlarda MNPYE'nin yüzey kaplama $(\theta)$ değerleri belirlenerek çeşitli adsorpsiyon izotermlerine uygunluğu araştırılmıştır. En uygun adsorpsiyon izotermi 
Langmuir adsorpsiyon 1zotermi olarak belirlenmiş (Şekil 4) ve Eşitlik 3 ile ifade edilmiştir.

$$
\frac{C_{i n h}}{\theta}=\frac{1}{K_{a d s}}+C_{i n h}
$$

Eşitlik 3'te, $\theta$; yüzey kaplama kesridir $\mathrm{C}_{\text {inh }}$; MNPYE'nin konsantrasyonudur ve $\mathrm{K}_{\mathrm{ads}}$; adsorpsiyon sürecinin denge sabitidir. Şekil 4'te, $\quad C_{\text {inh }} / \theta$ 'nın $\quad C_{\text {inh }}$ 'e karşı bağlılığ gösterilmektedir. Adsorpsiyon parametrelerini hesaplamak için en küçük kareler yöntemi kullanılarak Şekil 4'teki grafik çizilmiş ve regresyon katsayısı 0,9997 olarak belirlenmiştir. Bu da deneysel verilerin tek katmanlı adsorpsiyon özelliği sergileyen Langmuir izotermiyle uyumlu olduğunu göstermektedir. Bu tür izoterm, elektrot yüzeyinde adsorbe edilen türler arasında etkileşimin olmadığı varsayımını içermektedir [32]. Elde edilen doğrusal grafiğin denkleminin kaymasından, $\mathrm{K}_{\mathrm{ads}}$ değeri, 39,84 L/g olarak hesapland.

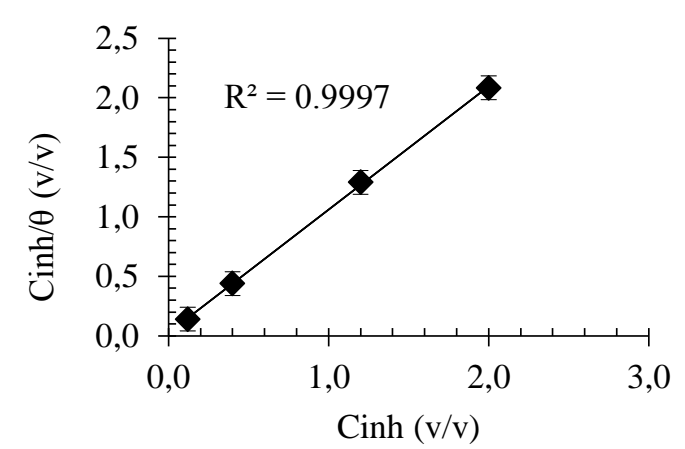

Şekil 4. MNPYE'nin farkli konsantrasyonlarini içeren 0,5 M HCI çözeltisinde YÇ elektrot için langmuir adsorpsiyon grafiğgi

$\mathrm{K}_{\mathrm{ads}}$, (Standart Gibbs Serbest Adsorpsiyon enerjisi) $\Delta \mathrm{G}^{\circ}{ }_{\text {ads }}$ ile arasındaki ilişki Eşitlik 4'teki gibidir [33].

$$
\Delta G_{a d s}^{o}=-R T \ln \left(C_{H_{2} O} K_{a d s}\right)
$$

Burada $\mathrm{R}$, evrensel gaz sabiti, $\mathrm{T}$ termodinamik sicaklığı ve $\mathrm{C}_{\mathrm{H} 2 \mathrm{O}}$ solüsyondaki su konsantrasyonunu göstermektedir.
Hesaplanan $\Delta \mathrm{G}^{\circ}$ ads değeri, -26,30 $\mathrm{kJ} \mathrm{mol}^{-1}$, dir. Genel olarak, -20 $\mathrm{kJ} \mathrm{mol}^{-1}$ veya daha düşük $\Delta \mathrm{G}^{\circ}$ ads değerleri, inhibitör molekülleri ve metal yüzeyi arasındaki elektrostatik etkileşimi yani fiziksel adsorpsiyonu ifade eder; $-40 \mathrm{~kJ} \mathrm{~mol}^{-1}$ veya daha büyük olanlar, koordine tipi bağ oluşturmak için inhibitör moleküllerinden metal yüzeyine yük paylaşımını veya transferini içerir, yani kimyasal adsorpsiyonu ifade eder [34-36]. Bu tür kriterlere dayanarak kimyasal ve fiziksel adsorpsiyon arasında, özellikle yüklü türler metal yüzeyine adsorbe edildiğinde ayırt etmek zordur. Bu durum açıkça ifade edilemez çünkü fiziksel adsorpsiyon kimyasal adsorpsiyonun ilk adımı olarak kabul edilir. Bu nedenle, YÇ yüzeyindeki moleküllerin adsorpsiyonunda, muhtemelen fiziksel adsorpsiyona ek olarak kimyasal adsorpsiyon da olabilir. Bu çalışmada, $\Delta \mathrm{G}^{\circ}$ ads değeri, MNPYE bileşenlerinin adsorpsiyonunda kimyasal adsorpsiyonun yanı sira baskın fiziksel adsorpsiyonun da olası olduğunu göstermektedir [37].

\subsection{Sıfır Yük Potansiyeli (PZC)}

Moleküllerin metal yüzeyine adsorpsiyonu, metalin yükü, dipol momenti, kimyasal yapısı ve çevresinde bulunan diğer iyonik türlere bağlıdır. Metalin yüzey yükü, sıfır yük potansiyeline (PZC) göre korozyon potansiyelinin $\left(\mathrm{E}_{\mathrm{kor}}\right)$ yeri belirlenerek bulunur. Uygulanan potansıyele (V) karşı EIS verilerinden elde edilen çift tabaka kapasitansı $\left(\mathrm{C}_{\mathrm{dl}}\right)$ değerlerine göre çizilen şekil, PZC'yi tespit etmek için kullanıldı. Çoğunlukla, elde edilen eğrı üzerindeki minimum değer, metalin yüzey yükü olarak ifade edilir. $\mathrm{E}_{\mathrm{r}}=\mathrm{E}_{\mathrm{kor}}-\mathrm{PZC}$ farkına göre, metalin net yüzey yükü, asidik ortamda tanımlanabilir. Şekil 5'te, 1 saat daldırma süresinden sonra 2,00 g L-1MNPYE ile 0,5 M HCI içinde YÇ'nin uygulanan potansiyeline karşı $\mathrm{C}_{\mathrm{dl}}$ şekli verilmiştir. Şekil 5'te görüldüğü gibi, parabolün minimum noktasına karşılık gelen potansiyel değeri PZC olarak adlandirılan $-0,469 \mathrm{~V} \quad(\mathrm{Ag} / \mathrm{AgCl})^{\prime}$ dir. Şekil 5'e göre, $\mathrm{E}_{\mathrm{r}}$ negatiftir ve potansiyeli $-0,013 \mathrm{~V}(\mathrm{Ag} / \mathrm{AgCl})$ 'tur. $\mathrm{Bu}$ nedenle, korozyon potansiyelinde YÇ yüzey yükü negatiftir. Bundan dolayı, negatif yüklü YÇ yüzeyine, asidik çözelti içindeki protonlanmış MNPYE bileşenleri adsorbe olabilir. 


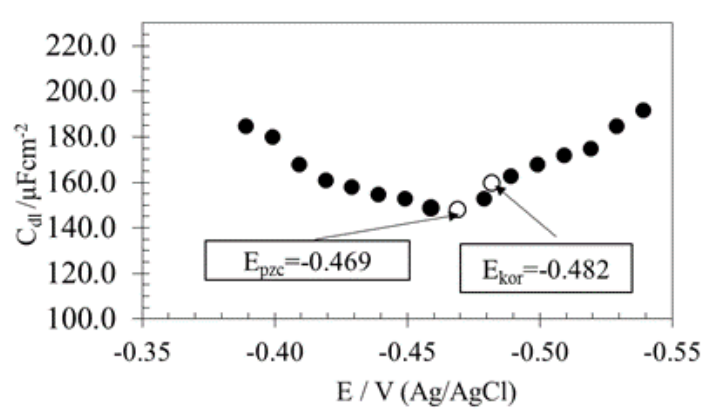

Şekil 5. \%2,00 MNPYE içeren $0,5 \quad \mathrm{M} \quad \mathrm{HCl}$ çözeltisinde $\mathrm{C}_{\mathrm{dl}}$ 'ye karşı uygulanan potansiyelin grafiği

\subsection{SEM Analizleri}

Şekil 6'da, 2,00 $\mathrm{g} \mathrm{L}^{-1}$ MNPYE içeren ve içermeyen $0,5 \mathrm{M} \mathrm{HCI}$ içinde 2 saat dalma süresinden sonra elde edilen SEM görüntülerini göstermektedir. Şekil 6a'da görüldüğü gibi, MNPYE içermeyen YÇ yüzeyinde, bazı çatlaklar, küçük çukurlar ve korozif çözeltinin saldırısından kaynaklanan YÇ korozyon ürünlerinin birikintileri gibi hasarlar görülür. Oysa MNPYE 'nin varlığında YÇ yüzeyinde koruyucu bir tabakanın varlığı görülmektedir (Şekil 6b). MNPYE bileşenlerinin, YÇ yüzeyinde bir bariyer tabakası oluşturarak asidik ortamda korozyona karşı koruduğu açıktır.
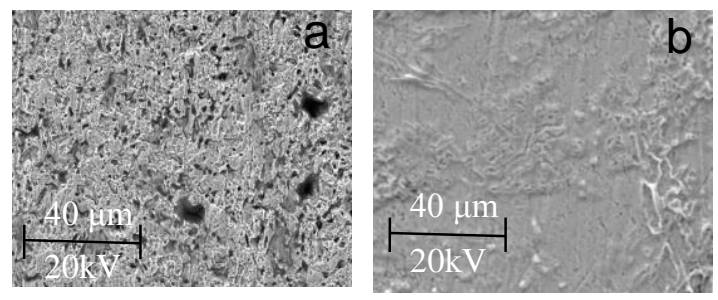

Şekil 6. \%2,00 MNPYE içermeyen, (a) ve içeren (b) $0,5 \mathrm{M} \mathrm{HCl}$ çözeltilerinde $\mathrm{YCC}$ elektrot için 2 saat daldırmadan sonra elde edilen SEM görüntüleri.

\section{5. İnhibisyon Mekanizması}

MNPYE'nin gözlenen inhibisyon etkisi, karışık tipteki adsorpsiyonu takiben YÇ yüzeyindeki MNPYE bileşenlerinin kollektif adsorpsiyonuna, yani yüklü metal yüzeye karşı MNPYE bileşenlerinin elektrostatik etkileşimi yoluyla veya heteroatomların yalın çift elektronları aracılığıyla kollektif adsorpsiyonuna bağlanır. PZC'ye bağlı olarak, MNPYE'nin inhibisyon mekanizmas1, asidik çözelti içinde YÇ yüzeyi üzerindeki protonlanmış MNPYE bileşenlerinin adsorpsiyonuyla ifade edilebilir. Protonlanmış MNPYE bileşenleri su molekülleriyle rekabet ederek adsorbe olur. MNPYE bileşenleri anodik ve katodik alanları kontrol eder. Katodik bölgelerdeki adsorpsiyon, asidik ortamda protonlu MNPYE bileşenleri tarafindan oluşturulmakla birlikte, anodik bölgelerdeki adsorpsiyon, YÇ yüzeyindeki MNPYE bileşenlerinde bulunan heteroatomlar üzerindeki yalın çift elektronların Fe iyonları ile arasındaki verici-alıcı etkileşimiyle oluşur. $\mathrm{Bu}$, hidrojenin oluşum reaksiyonunu geciktirir. $\mathrm{Bu}$ nedenle MNPYE, mevcut bileşenleri vasıtasıyla YÇ yüzeyinde asit atağını sınırlandıran koruyucu bir tabaka oluşturması sonucu etkili bir inhibitör olarak düşünülebi

\section{SONUÇ VE ÖNERILER}

MNPYE'nin 0.5 M HCI'de YÇ için yüksek inhibisyon verimi gösterdiği sonucuna varılabilir. Deneysel sonuçlar incelendiğinde, inhibisyon veriminin MNPYE'nin artan konsantrasyonu ile arttığını ve 2,00 $\mathrm{g} \mathrm{L}^{-1}$ MNPYE içeren 0,5 M HCI'de maksimum değere ulaştığı görülmektedir. Polarizasyon eğrilerine göre, MNPYE hem anodik hem de katodik bölgelerde inhibisyonu sağlamaktadır. Polarizasyon direnci, MNPYE içermeyen asit çözeltileri için elde edilen değerle karşıllaştırıldığında 2,00 $\mathrm{g} / \mathrm{L}^{-1}$ MNPYE içeren $0,5 \mathrm{M}$ HCI'de en yüksek değerdedir ve MNPYE'nin YÇ yüzeyine adsorpsiyonu Langmuir adsorpsiyon izotermini uymaktadır. MNPYE bileşenlerinin YÇ yüzeyine adsorpsiyonu SEM yüzey incelemesinde görülmektedir.

\section{TEŞEKKÜR}

Bu çalışmanın yapılmasında destek veren Çukurova Üniversitesi Fen-Edebiyat Fakültesi Kimya Bölümü Fizikokimya Araştırma Lab.'’na, SEM görüntüleri için Merkez Lab.'a, deneysel çalışmalarda yardımcı olan Dr. Öğr. Üyesi Murat 
FARSAK'a ve değerli katkıları için Prof. Dr. Gülfeza KARDAŞ'a çok teşekkür ederim.

\section{KAYNAKLAR}

1. Raja, P.B., Qureshi, A.K., Rahim, A.A., Osman, H., Awang, K., 2013. Corros. Sci.: Neolamarckia Cadamba Alkaloids as Eco Friendly Corrosion Inhibitors for Mild Steel in 1 M HCl Media, 69, 292-301.

2. Bentrah, H., Rahali, Y., Chala, A., 2014. Corros. Sci.: Gum Arabic as an Eco-friendly Inhibitor for API 5L X42 Pipeline Steel in HCl Medyum, $82,426-431$.

3. Ansari, K.R., Quraishi, M.A., 2014. J. Ind. Eng. Chem.: Bis-Schiff Bases of Isatin as New Anda Environmentally Benign Corrosion Inhibitor for Mild Steel, 20, 2819-2829.

4. Pournazari, S.H., Moayed, M.H., Rahimizadeh, M., 2013. Corros. Sci.: In Situ Inhibitor Synthesis form Admixture of Benzaldehyde and Benzene-1,2-diamine Along with $\mathrm{FeCl}_{3}$ Catalyst as a New Corrosion Inhibitor for Mild Steel in 0.5 M sulphuric acid, 71, 20-31.

5. Dasami, P., Parameswari, K., Chitra, S., 2015. Measurement: Corrosion Inhibition of Mild Steel in $1 \mathrm{MH}_{2} \mathrm{SO}_{4}$ by Thiadiazole Schiff Bases, 69, 195-201.

6. Verma, C., Ebenso, E.E., Bahadur, I., Obot, I.B., Quraishi, M.A., 2015. J. Mol. Liq.: Aryl Sulfonamidomethylphosphonates as New Class of Green Corrosion Inhibitors for Mild Steel in 1M HCl: Electrochemical, Surface and Quantum Chemical Investigation, 212, 209-218.

7. Noor, E.A., 2008. J. Eng. Appl. Sci.: Comparative Study on the Corrosion Inhibition of Mild Steel by Aqueous Extract of Fenugreek Seeds and Leaves in Acidic Solutions, 3, 23-30.

8. Okafor, P.C., Ikpi, M.E., Ekanem, U.I., Ebenso, E., 2013. Int. J. Electrochem. Sci.: Effects of Extracts from Nauclea Latifolia on the Dissolution of Carbon Steel in $\mathrm{H}_{2} \mathrm{SO}_{4}$ Solutions, 8, 12278-12286.

9. Patel, N.L., Jauhariand, S., Mehta, G.N., AlDeyab, S.S., Warad, I., Hammouti, B., 2013. Int. J. Electrochem. Sci.: Mild Steel Corrosion Inhibition by Various Plant Extracts in $0.5 \mathrm{M}$ Sulphuric Acid, 8, 2635-2655.
10. Mourya, P., Banerjee, S., Singh, M.M., 2014. Corros. Sci.: Corrosion Inhibition of Mild Steel in Acidic Solution by Tagetes Erecta (Marigold flower) Extract as a Green Inhibitor, 85, 352-363.

11. Singh, P., Makowska-Janusik, M., Slovensky, P., Quraishi, M.A., 2016. J. Mol. Liq.: Nicotinonitriles as Green Corrosion Inhibitors Formild Steel in Hydrochloric Acid: Electrochemical, Computational and Surface Morphological Studies, 220, 71-81.

12. Ituen, E., Akaranta, O., James, A., 2016. J. Mol. Liq.: Green Anticorrosive Oilfield Chemicals from 5-hydroxytryptophan and Synergistic Additives for X80 Steel Surface Protection in Acidic Well Treatment Fluids, 224, 408-419.

13. Alaneme, K.K., Olusegun, S.J., Adelowo, O.T., 2016. Alexandria Eng. J.: Corrosion Inhibition and Adsorption Mechanism Studies of Hunteria Umbellata Seed Husk Extracts on Mild Steel Immersed in Acidic Solutions, 55, 673-681.

14. Bellini, E., Giordani, E., Roger, J.P., 2000. Informatore Agrario: The Mulberry Tree for Fruit Production [Morus spp.]., 56, 89-93.

15. Gara, S., Jaisankar, P., Singh, J.K., Elango, A., 2012. Corros. Sci.: A Comprehensive Study on Crude-lice Extract of Artemisia pallens (Asteraceae) anda ita Active Component as Effective Corrosion Inhibitors of Mild Steel in Acil Solutions, 60, 193-204.

16. Li, X., Denge, S., Fu, H., Xie, X., 2014. Corros Sci.: Synergistic Inhibition Effects of Bamboo Leaf Extract/major Components anda Iodide Son on the Corrosion of Steel in $\mathrm{H}_{3} \mathrm{PO}_{4}$ Solutions, 78, 29-42.

17. Sanchez, C., Renard, D., Robert, P., Schmitt, C., Lefebvre, J., 2001. Food Hydrocoll: Structure and Rheological Properties of Acacia Gum Dispersions, 16, 257-267.

18. Umoren, S.A., Obot, I.B., Ebenso, E.E., Okafor, P.C., Ogbobe, O., Oguzie, E.E., 2006. Mater. Des.: Gum Arabic as a Potential Corrosion Inhibitor for Aluminium in Alkaline Medium and its Adsorption Characteristics, Anti-corros Methods, 53(5), 277.

19. Umoren, S.A., 2008. Cellulose: Inhibition of Aluminium and Mild Steel Corrosion in Acidic Medium Using Gum Arabic, 15, 751-761. 
20. Hamdy, A., El-Gendy, N.Sh., 2013. Egypt. J. Pet.: Thermodynamic, Adsorption and Electrochemical Studies for Corrosion Inhibition of Carbon Steel by Henna Extract in Acid Medium, 22, 17-25.

21. Lebrini, M., Legrenee, M., Vezin, H., Traisnel, M., Bentiss, F., 2007. Experimental and Theoretical Study for Corrosion Inhibition of Mild Steel in Normal Hydrochloric Acid Solution by Some New Macrocyclic Polyether Compounds, 49, 2254-2269.

22. Reisde, F.M., Melo, H.G., Costa, I., 2006. Electrochim. Acta: EIS Investigation on A1 5052 Alloy Surfacepreparation for Self Assembling Monolayer, 51, 1780-1788.

23. Roy, P., Karfa, P., Adhikari, U., Sukul, D., 2014. Corros. Sci.: Corrosion Inhibition of Mild Steel in Acidic Medium by Polyacrylamide Grafted Guar Gum with Various Grafting Percentage: Effect of Intramolecular Synergism, 88, 246-253.

24. El Achouri, M., Kertit, S., Gouttaya, H.M., Nciri, B., Bensouda, Y., Perez, L., Infante, M.R., Elkacemi, K., 2001. Prog. Org. Coat.: Corrosion Inhibition of Iron in $1 \mathrm{M} \mathrm{HCl}$ by Some Gemini Surfactants in the Series of Alkanediyl- $\alpha, \omega$-bis-(Dimethyl Tetradecyl Ammonium Bromide), 43, 267-273.

25. Yadav, D.K., Quraishi, M.A., 2012. Ind. Eng. Chem. Res.: Electrochemical Investigation of Substituted Pyranopyrazoles Adsorption on Mild Steel in Acid Solution, 51, 8194-8210.

26. Verma, C., Quraishi, M.A., Singh, A., 2015. J. Taiwan. Ins.Chem. Eng.: 2-Aminobenzene-1,3Dicarbonitriles as Green Corrosion Inhibitor for Mild Steel in $1 \mathrm{M} \mathrm{HCl}$ : Electrochemical, Thermodynamic, Surface and Quantum Chemical Investigation, 49, 229-239.

27. Odewunmi, N.A., Umoren, S.A., Gasem, Z.M., 2015. Journal of Environmental Chemical Engineering.: Watermelonwaste Products as Green Corrosion Inhibitors for Mild Steel in $\mathrm{HCl}$ Solution, 3, 286-296.

28. Hazwan Hussin, M., Abdul Rahim, A., Ibrahim, M.N., Brosse, N., 2016. The Capability of Ultrafiltrated Alkaline and Organosolv Oil Palm (Elaeis Guineensis) Fronds Lignin as Green Corrosion Inhibitor for Mild Steel in $0.5 \mathrm{M} \mathrm{HCl}$ Solution, Measurement, 78, 90-103.
29. Khaled, K., 2003. Electrochim. Açta: The Inhibition of Benzimidazole Derivatives on Corrosion of Iron in1 M HCl Solutions, 48, 2493-2503.

30. Nesakumar, T., Edison, J.I., Atchudan, R., Pugazhendhi, A., Lee, Y.R., Sethuraman, M.G., 2018. J. Mol. Liq.: Corrosion Inhibition Performance of Spermidine on Mild Steel in Acid Media, 264, 483-489.

31. Satapathy, A.K., Gunasekaran, G., Sahoo, S.C., Amit, K., Rodrigues, P.V., 2009. Corros. Sci.: Corrosion Inhibition by Justicia Gendarussa Plant Extract in Hydrochloric Acid Solution, 51, 2848-2856.

32. Elayyachy, M., El Idrissi, A., Hammouti, B., 2006. Corros. Sci.: New thio-compounds as Corrosion Inhibitor for Steel in $1 \mathrm{M} \mathrm{HCl}, 48$, 2470-2479.

33. Morad, M.S., 2008. Corros. Sci.: Inhibition of iron Corrosion in Acid Solutions by Cefatrexyl: Behaviour Near and at the Corrosion Potential, 50, 436-448.

34. Ansari, K.R., Quraishi, M.A., Singh, A., 2014. Corros. Sci.: Schiff's Base of Pyridyl Substitutedtriazoles as New and Effective Corrosion Inhibitors for Mild Steel Inhydrochloric Acid Solution, 79, 5-15.

35. Ahamad, I., Prasad, R., Quraishi, M.A., 2010. Corros. Sci.: Thermodynamic, Electrochemical Andquantum Chemical Investigation of Some Schiff Bases as Corrosion Inhibitorsfor Mild Steel in Hydrochloric Acid Solutions, 52, 933-942.

36. Li, W., He, Q., Zhang, S., Pei, C., Hou, B., 2008. J. Appl. Electrochem.: Some New Triazole Derivatives Asinhibitors for Mild Steel Corrosion in Acidic Medium, 38, 289-295.

37.Zhang, X., Zheng, Y., Wang, X., Yan, Y., Wu, W., 2014. Ind. Eng. Chem. Res.: Corrosion Inhibition of N80 Steel Using Novel Diquaternary Ammonium Salts in $15 \%$ Hydrochloric Acid, 53, 14199-14207. 